\title{
EVALUATION THE PERFORMANCE OF HYPERSPECTRAL REFLECTANCE SENSOR FOR ESTIMATING THE HARDNESS AND BIOCHEMICAL PARAMETERS OF TOMATO FRUITS
}

\author{
Elsayed, S. ${ }^{(1)}$ M. I. Ghazy ${ }^{(2)}$
}

\begin{abstract}
Mechanical and biochemical analysis for assessing tomato fruit quality in food processing are the traditional methods, which leads to the destruction of fruits and is time consuming. Similarly, for valuating large quantities of tomato fruits for export, numerous observations are required to characterize them; such methods cannot easily account for rapid changes in these parameters. In this study the performance of hyperspectral passive reflectance sensing at various ripening degrees of tomato fruits was test its relationship to hardness, fruit water content, soluble solids content percentage, titratable acidity and $\mathrm{pH}$ via simple linear regression analysis. The results showed that statistically significant relationships between all spectral reflectance indices derived from near infrared (NIR) with measured parameters were found. The spectral index $R_{1000} / R_{716}$, showed the highest coefficients of determination for the hardness of tomato $\left(R^{2}=0.85 * * *\right)$, the spectral index $R_{970} / R_{964}$, showed the highest coefficients of determination for the fruit water content $\left(R^{2}=\right.$ $\left.0.70^{* * *}\right)$, soluble solids content $\left(R^{2}=0.86^{* * *}\right)$ and titratable acidity $\left(R^{2}=\right.$ $0.82 * * *)$ as well as the spectral index $R_{970} / R_{726}$, showed the highest coefficients of determination for the titratable acidity $\left(R^{2}=0.78 * * *\right)$ of tomato fruits. In conclusion, the using of spectral sensing may open an avenue in post-harvest and food processing for fast, high-throughput assessments mechanical and biochemical of tomato fruits.
\end{abstract}

\section{INTRODUCTION}

Tomato is one of the most widely consumed vegetable crops in the world, not only because of its volume, but the main supplier of

L several phytonutrients and providing an important nutritional value to human diet and its important role in human health (Willcox et al. 2003).

\footnotetext{
1 Assoc. Prof. of Agric. Eng., Evaluation of Natural Resources Department, Environmental Studies and Research Institute, Sadat City University. 2 Lecturer of Agric. Eng., Faculty of Agric., Mansoura University.
} 
Productive postharvest management and harvest time of tomatoes demand knowledge of the postharvest physiology or biochemical quality parameters to determine the best handling practices to maintain and create high fruit quality during the ripening stage. Ripening is actually part of the natural senescence regarding tomatoes fruits. It is an irreversible process that contributes to organelle disruption and changes in chemical constituents. There are different interesting mechanical and biochemical parameters, such as hardness, fruit water content, soluble solids content (SSC) and titratable acidity (T. Acidity) and $\mathrm{pH}$ which can be used as diagnostic indicators of tomato quality. In general, fruits are sorted manually or automatically on the basis of size, color, and surface defects such as bruises. However, dry matter content, total soluble solids content, sugar content, juice acidity and firmness are important internal quality attributes of fruit products. Actual methods for the assessment of tomato fruit quality are generally based on biochemical analysis, which leads to destruction of fruits and is time consuming. Fruit analysis is important for detecting tomato quality; nevertheless, destructive methods are not appropriate. Similarly, for valuating large quantities of tomato fruits for export, numerous observations are required for their characterization; such methods cannot easily account for rapid changes in these parameters arising from changes in environmental conditions. In contrast, highthroughput passive reflectance sensors using spectral reflectance measurements has the potential to provide more information for making better-informed decisions at the tomato scale in real time. Passive sensor systems depend on sunlight as a source of light, which allows hyperspectral information to be obtained in the visible and near-infrared range (Erdle et al., 2011; Mistele et al., 2012; Elsayed et al., 2015a; Nagy et al., 2016). A strong interest for spectrometry (as a non-destructive technique), is that information can be collected on the same fruit, at different times. This means that it gives access, not only to punctual information, but also to the dynamics of the measured characteristics. Regarding tomatoes, nice sets of data have been obtained that allowed to predict color and pigment content with good accuracy, as well as firmness to a lesser extent using the 400 - $1500 \mathrm{~nm}$ range (Clément et al., 2008). 
Some previous studies assessed the quality parameters of fruits by using spectroscopic measurements (Rutkowski et al., 2008; Deng et al., 2010; Moghimi et al., 2010; Jha et al., 2012). Rutkowski et al. (2008) found that the index of anthocyanin (NAI), calculated as $\left(\mathrm{R}_{780}-\mathrm{R}_{570}\right) /\left(\mathrm{R}_{780}+\mathrm{R}_{570}\right)$, was significantly correlated with the fruit firmness and titratable acidity in 'Golden Delicious' apples. Partial least square regression (PLSR) based on spectral reflectance from 400-1000 nm, processed with standard normal variate correction $(\mathrm{SNV})$, median filter and $1^{\text {st }}$ derivative, was used to predict the acidity in kiwi fruits (Moghimi et al., 2010). Jha et al. (2012) applied reflectance spectroscopy to measure SSC and $\mathrm{pH}$ in seven mango cultivars. The optimal results were obtained by using PLSR models based on $2^{\text {nd }}$ derivative spectra in the $1600-1799 \mathrm{~nm}$ range. The reflectance spectrum at $988 \mathrm{~nm}$ was significantly correlated with the soluble solids content and vitamin C content of oranges (Deng et al., 2010).

The scientific hypothesis raised in this study investigates whether changes in biochemical quality parameters can be reflected by changes in spectral reflectance measurements based on the change in skin color of tomato fruits from green to red. Therefore, it is very important to develop high throughput sensing methods for assessment water stress in crops, which should be reliable, fast, simple, practical, and economic.

The purpose of this work is to assess whether spectral reflectance indices can estimate the hardness and biochemical parameters of tomato under different ripening levels from green to red.

\section{MATERIAL AND METHODS}

\subsection{Experimental information}

The experiments were conducted at the Research Station of Sadat City University in Egypt (Latitude: N 30 $2^{\prime} 41.185^{\prime \prime}$, Longitude: E $31^{\circ} 14^{\prime}$ $\left.8.1625^{\prime \prime}\right)$. The fruit samples of the tomato cultivar (GS-12) were selected at different ripening degrees (Fig. 1) to be assessed via passive reflectance and thereafter used for determining hardness, fruit water content (FWC), soluble solids content (SSC), titratable acidity and $\mathrm{pH}$. 

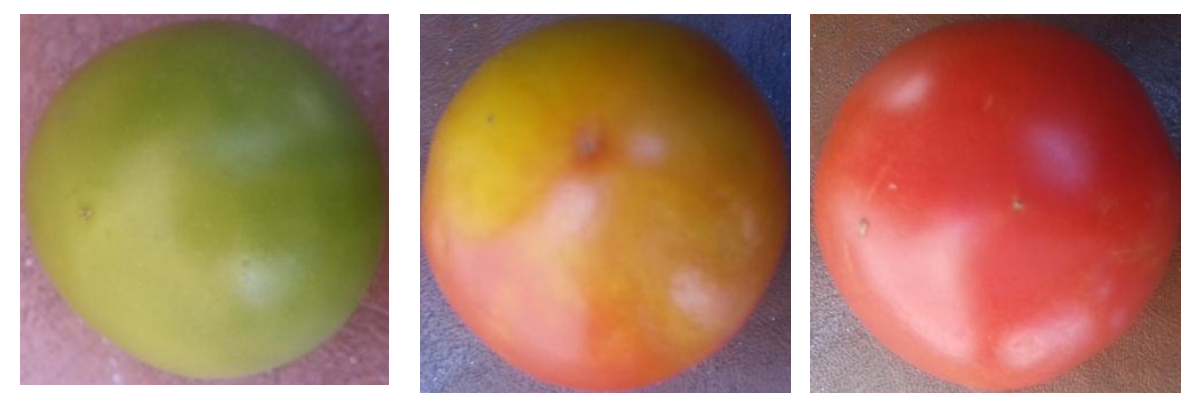

Fig.1.Tomatoes fruits were selected at different ripening degrees

\subsection{Hardness, soluble solids content percentage, titratable acidity and $\mathbf{p H}$} Pulp samples were squeezed and the obtained juice was used to determine the percentage of SSC using a hand refractometer according to A.O.A.C. (1980). The titratable acidity was determined in $5 \mathrm{~mL}$ of juice samples.

For the titration, $0.1 \mathrm{~N}$ sodium hydroxide and phenolphthalein as an indicator were used according to A.O.A.C. (1980). The $\mathrm{pH}$ was determined by potentiometric measurement made at $20{ }^{\circ} \mathrm{C}$ with $\mathrm{pH}$ meter according to A.O.A.C. (1980). The portable durometer (WESTport Rex Model: H1000 Mini-Dial Durometer) were used to estimate the hardness of fruits.

\subsection{Spectral reflectance measurements:}

A passive bi-directional reflectance sensor (tec5, Oberursel, Germany), measuring at wavelengths between 302-1148 nm with a bandwidth of 2 nm, was used. The handheld FieldSpec sensor (Fig.2) consists of two units: one unit is linked with a diffuser and measures the light radiation as a reference signal, while the second unit measures the tomato fruits reflectance with a fiber optic (Elsayed et al., 2015b). The aperture of the optics was $12^{\circ}$ and the field of view was $0.1 \mathrm{~m}^{2}$ from half meter distance. Three spectral measurements were taken for each fruit. Spectral measurements of eighteen tomato fruits under different ripening degrees were taken within 15 minutes on a sunny period to avoid changes in sun radiation, and the fiber optics were positioned at a height of $0.15 \mathrm{~m}$ with a zenith angle of $30^{\circ}$ above the tomato fruits to avoid producing a shadow. To guarantee complete reflectance by the tomato fruits, a black sheet was used to prevent spectral reflectance caused by the background. With the 
readings from the spectrometer unit, the tomato fruits' reflectance was calculated and corrected with a calibration factor obtained from a reference gray standard.

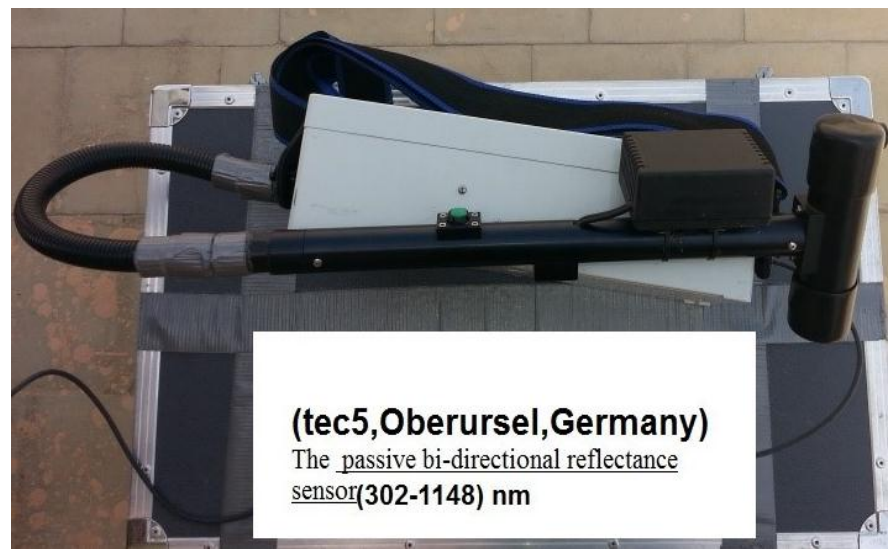

Fig.2. A passive bi-directional reflectance sensor measuring wavelengths between $302-1148 \mathrm{~nm}$.

\subsection{Statistical analysis}

\subsubsection{Selection of spectral reflectance indices}

In Table 1 seven spectral indices from different sources are listed with references. In this study, both known and novel indices were calculated and tested. A contour map analysis for all wavelengths of the hyperspectral passive sensor (from 302 to1148 nm) was used to select some spectral indices, which generally presented more stable and strong relationships with the hardness, fruit water content, soluble solids content, titratable acidity and $\mathrm{pH}$ of tomato fruits. All possible dual wavelengths combinations were evaluated based on a contour map analysis for the hyperspectral passive sensor. Contour maps are matrices of the coefficients of determination of all biochemical parameters of tomato fruits with all possible combinations of binary, normalized spectral indices. The R package "lattice" from the software $\mathrm{R}$ statistics version 3.0.2 ( $\mathrm{R}$ foundation for statistical computing 2013) was used to produce the contour maps from the hyperspectral reflectance readings, while eleven wavelengths $(716,726,740,780,940,950,960,964,970,992$, and $1000 \mathrm{~nm}$ ) were used to calculate reflectance indices, as indicated in Table 1. 


\subsubsection{Modeling of measurements}

Sigmaplot for Windows v.12 (Systat software Inc., Chicago) and SPSS 22 (SPSS Inc., Chicago, IL, USA) were used for the statistical analysis. Simple linear regressions were calculated to analyze the relationship between the spectral reflectance indices listed in Table 1 and the hardness and biochemical parameters. Coefficients of determination and significance levels were determined; $t$ nominal alpha values of $0.05,0.01$ and 0.001 were used.

Table 1. Spectral indices, formula and references of different spectral indices used in this study.

\begin{tabular}{lll}
\hline Spectral reflectance & Formula & References \\
\hline $\mathrm{R}_{970}$ and $\mathrm{R}_{950}$ & $\mathrm{R}_{970} / \mathrm{R}_{950}$ & Peñuelas et al., 1997 \\
$\mathrm{R}_{960}$ and $\mathrm{R}_{940}$ & $\mathrm{R}_{960} / \mathrm{R}_{940}$ & Elsayed et al., 2011 \\
$\mathrm{R}_{970}$ and $\mathrm{R}_{726}$ & $\mathrm{R}_{970} / \mathrm{R}_{726}$ & This work \\
$\mathrm{R}_{992}$ and $\mathrm{R}_{940}$ & $\mathrm{R}_{992} / \mathrm{R}_{940}$ & This work \\
$\mathrm{R}_{1000}$ and $\mathrm{R}_{716}$ & $\mathrm{R}_{1000} / \mathrm{R}_{716}$ & This work \\
$\mathrm{R}_{970}$ and $\mathrm{R}_{964}$ & $\mathrm{R}_{970} / \mathrm{R}_{964}$ & This work \\
$\mathrm{R}_{780}$ and $\mathrm{R}_{740}$ & $\mathrm{R}_{780} / \mathrm{R}_{740}$ & Mistele and Schmidhalter. \\
& & 2008 \\
\hline
\end{tabular}

\section{RESULTS AND DISCUSSION}

\subsection{Variation of hardness and biochemical parameters of tomato fruits}

The results indicated that biochemical parameters indices were generally affected by the stage of fruit ripening. There was a wide range between the minimum and maximum values for all studied biochemical parameters (Fig.3). Hardness were varied from 6.62 to $11.13\left(\mathrm{~kg} \mathrm{~cm}^{-2}\right)$, fruit water content from 0.91 to 0.93 , soluble solids content from 5.58 to $6.75, \mathrm{pH}$ from 4.12 to 4.7 and titratable acidity from 0.44 to 0.58 . The results showed that during fruit ripening hardness and titratable acidity were decreased and the skin color changed from green to red, while the values of fruit water content, $\mathrm{pH}$ and soluble solids content were increased. 


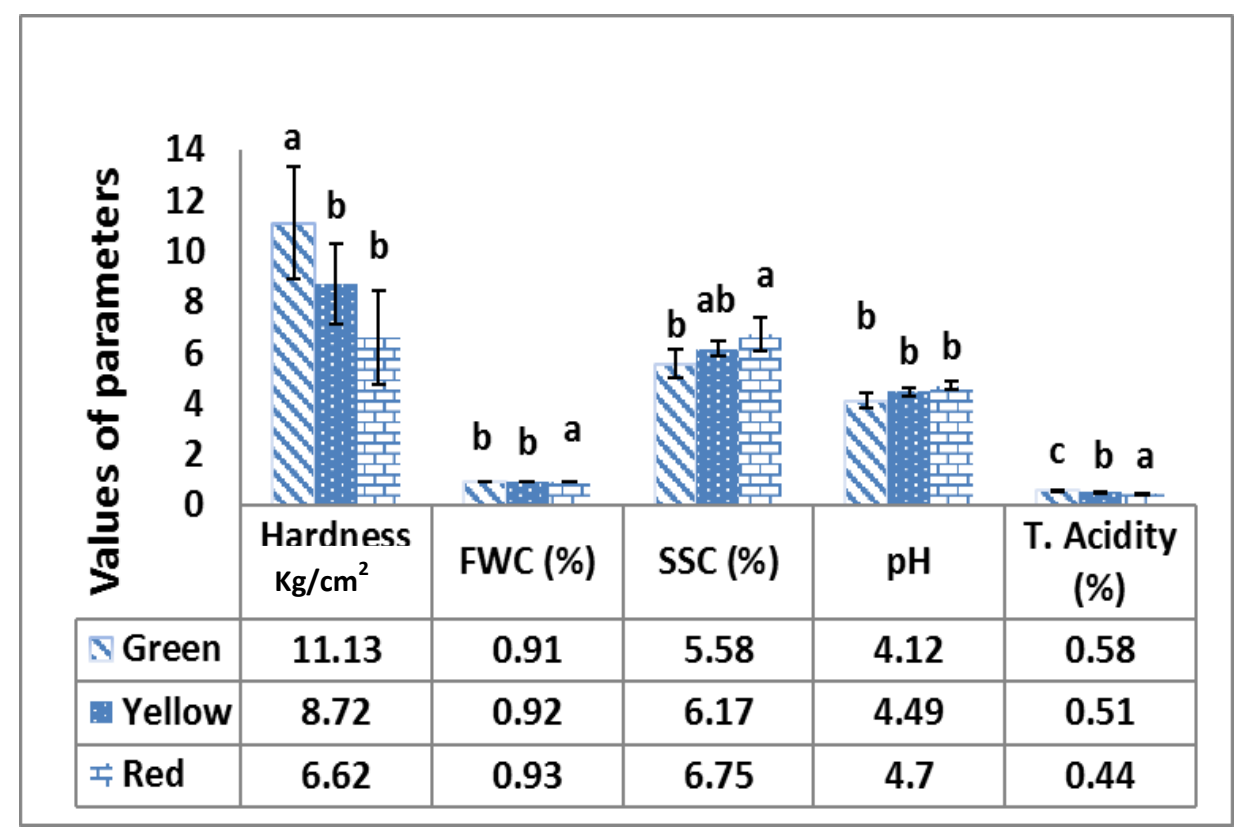

Fig. 3. Mean values (green, yellow and red) of hardness, fruit water content (FWC), soluble solids content (SSC), pH and titratable acidity (T. Acidity) of tomato fruits. Values with the same letter are not significantly different $(\mathrm{P} \geq 0.05)$ among cultivars according to Duncan's test. SD indicates standard deviation.

These results agree with other studies. For example, Medlicott et al. (1986) reported that during fruit ripening, the carotenoid concentration increased. Color changes in fruit are due to the disappearance of chlorophyll and the appearance of other pigments. Chloroplasts are transformed into chloroplasts containing yellow or red pigments (Lizada, 1993). The soluble solids content also increases during ripening because starch and sucrose are converted into glucose, which is the main substrate utilized in respiration (Chan and Kwok, 1975).

\subsection{Variation of Spectral Reflectance Curves for tomato fruits under different ripening levels}

There are also different between Spectral reflectance curves for tomato fruits under different ripening levels as showed in (Fig.4). Spectral reflectance curves were generally affected by fruit ripening stages. 
The spectral reflectance curve of yellow presented higher values compare to the spectral reflectance curve of green and red. The changes were observed in the red edge under fruit ripening stages. There was a clear difference in the water band at $970 \mathrm{~nm}$ under fruit ripening stages. Changes in fruit coloration, thus the differences in the spectral properties of tomato skin are demonstrating significant changes in pigment content and their compounds in fruits during ripening process.

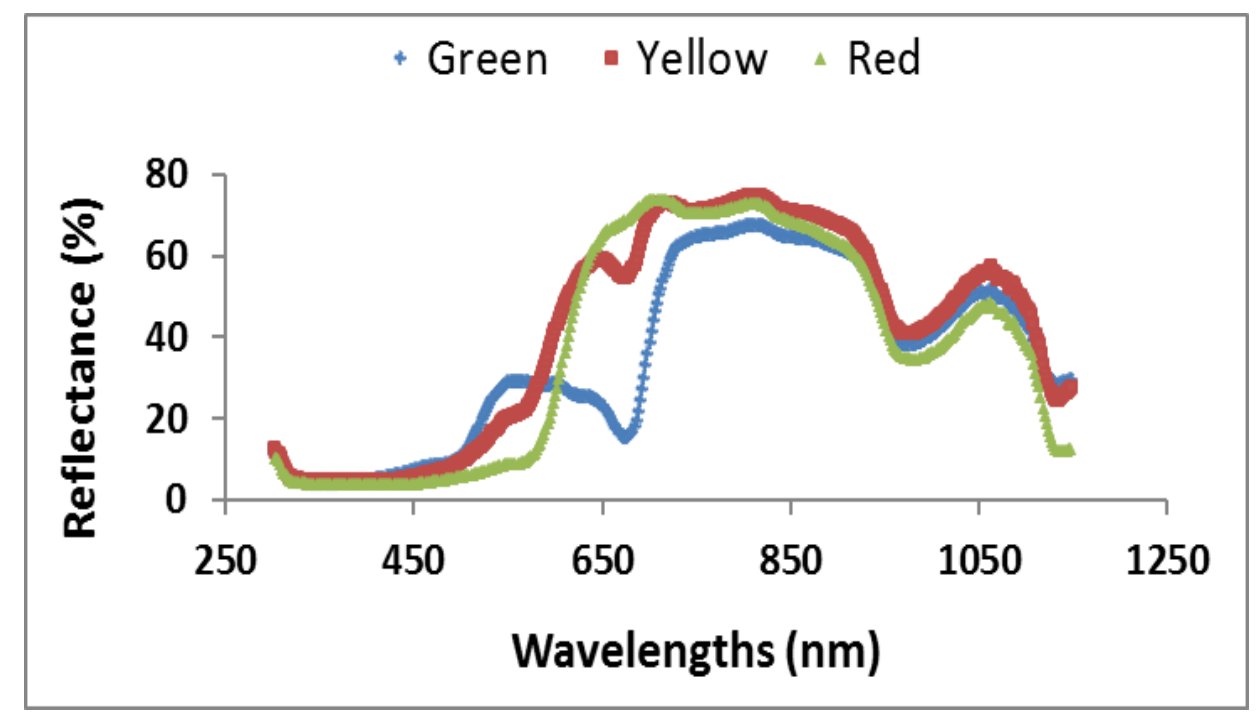

Fig. 4. Spectral Reflectance Curves for tomato fruits under different ripening levels.

Low chlorophyll-containing fruits (both in the case of yellow and red fruit varieties) had high reflectance in the range of chlorophyll absorption, between $600 \mathrm{~nm}$ and $700 \mathrm{~nm}$, whereas considerable spectral characteristics were not observed in the NIR range with high reflectance values. Decrease in reflectance (also for unripe fruits) was observed in the range of 900-970 wavelength range, which relates to the moisture content.

\subsection{Contour map analysis of the hyperspectral data}

A contour map analysis produced the coefficients of determination (R2) of the measurements for all dual wavelengths combinations from 302 to $1148 \mathrm{~nm}$ as spectral index. Contours of the matrices of the hyperspectral 
passive sensor presented generally more distinct relationships with all biochemical parameters. The contour map analysis of the relationship between the spectral indices with hardness, fruit water content, $\mathrm{pH}$, soluble solids content and titratable acidity are shown in (Figs. 5a, b, c, d and e). A contour map presented a larger range of indices with similar wavelength contain information relevant for the all biochemical parameters. The contours of the matrices of the spectral passive sensor presented stronger relationships between all biochemical parameters of tomato fruits with near infrared wavelengths and the combination of visible and near infrared wavelengths than visible wavelengths. The averages of the correlation matrices resulting from the measurements, indicated by the coefficients of determination (R2) for all dual wavelengths combinations of $750-1000 \mathrm{~nm}$ as spectral indices for all fruits measurements, presented higher R2-values compared to all other two wavelength combinations. The reason of that the wavelengths 850 to $1000 \mathrm{~nm}$ being more affected by water status.

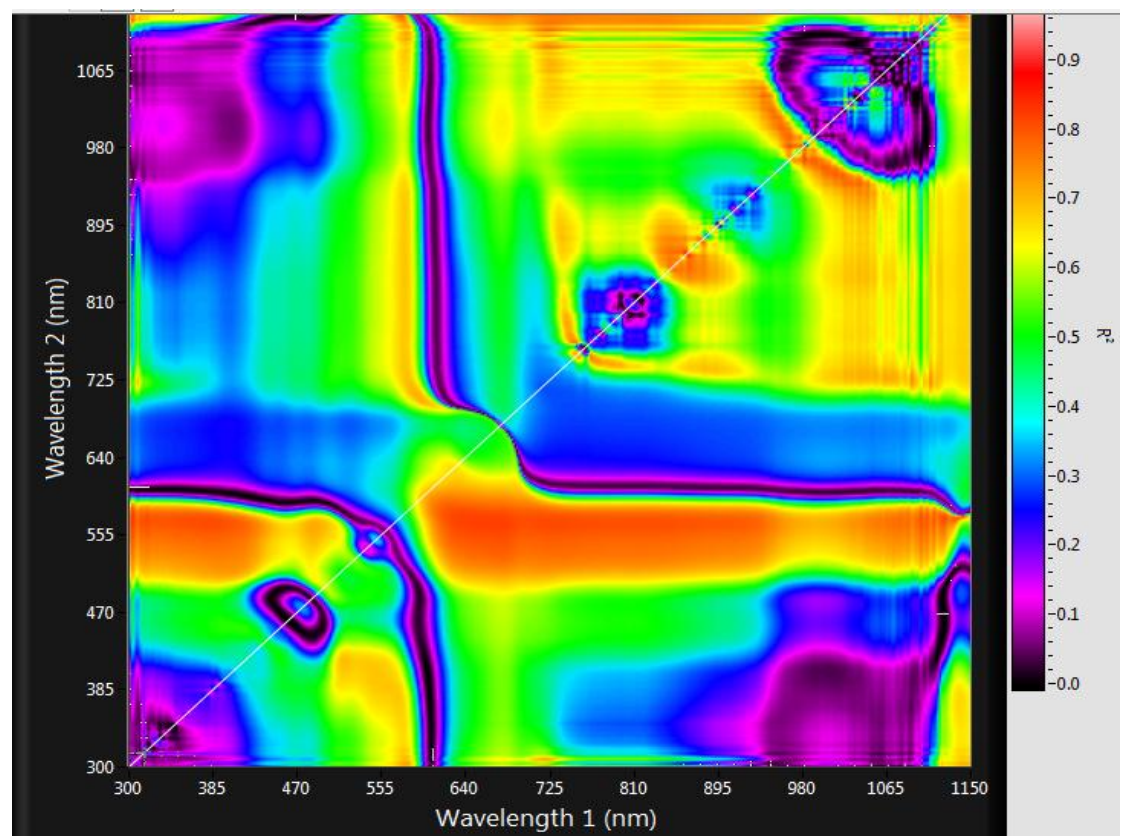

Fig.5a. Correlation matrices (contour maps) showing the coefficients of determination $\left(\mathrm{R}^{2}\right)$ for spectral index with hardness. 


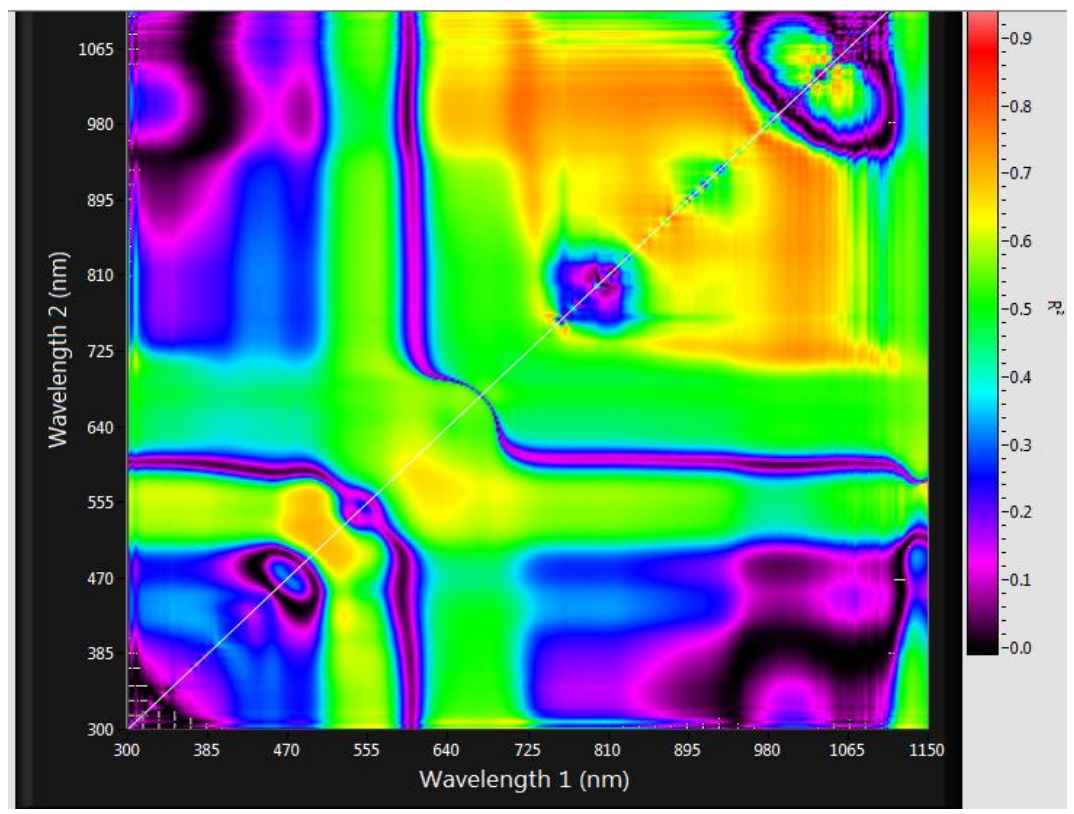

Fig.5b. Correlation matrices (contour maps) showing the coefficients of determination $\left(\mathrm{R}^{2}\right)$ for spectral index with Fruit water content (FWC).

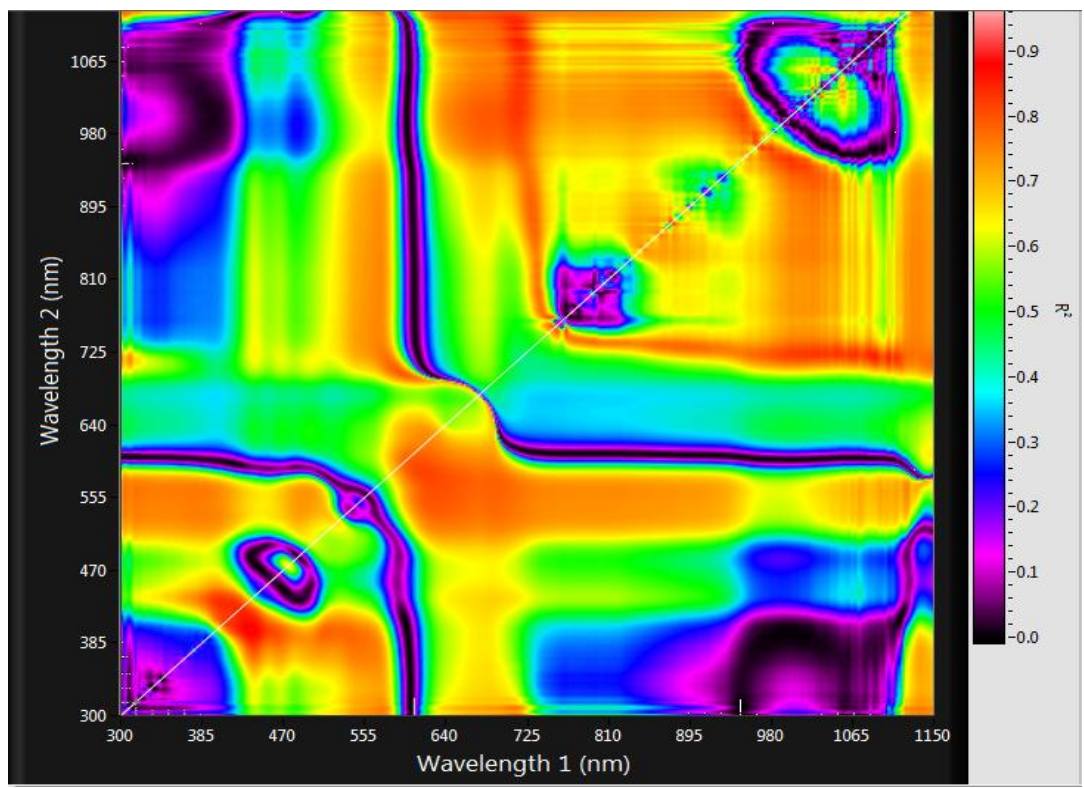

Fig.5C. Correlation matrices (contour maps) showing the coefficients of determination (R2) for spectral index with soluble solids content (SSC). 


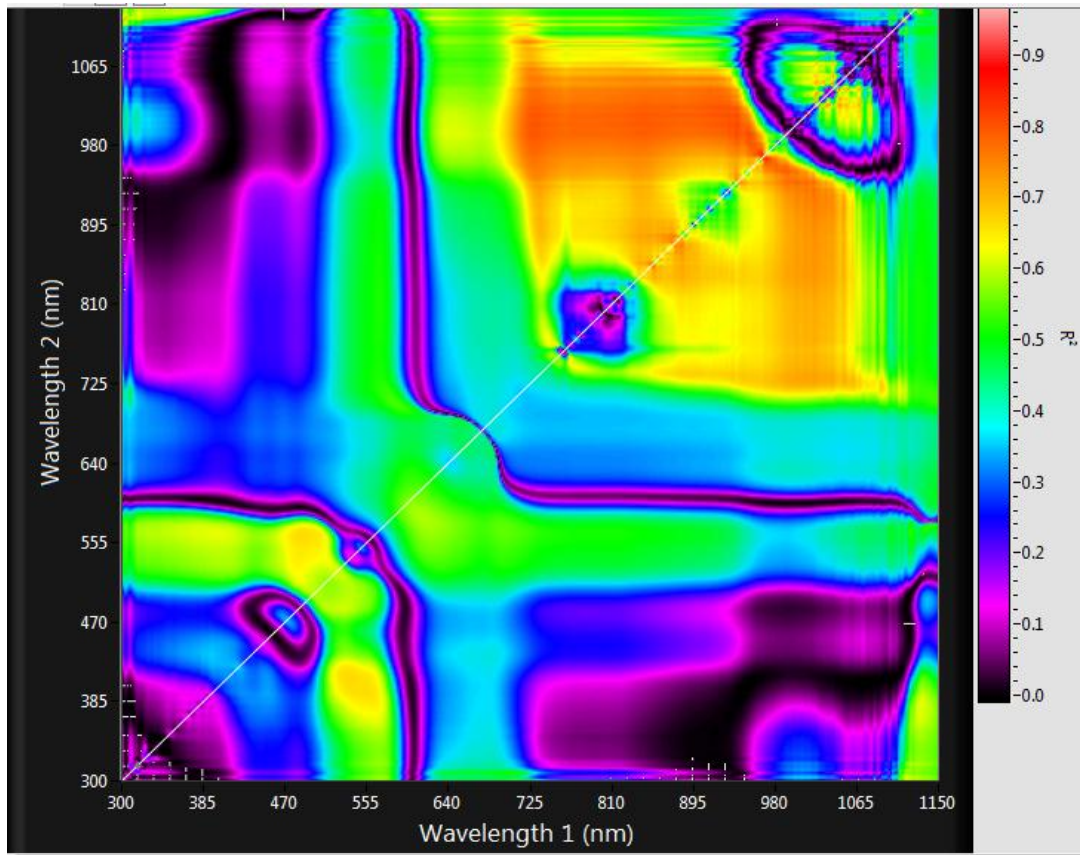

Fig.5d. Correlation matrices (contour maps) showing the coefficients of determination $\left(\mathrm{R}^{2}\right)$ for spectral index with Titratable acidity (T. Acidity).

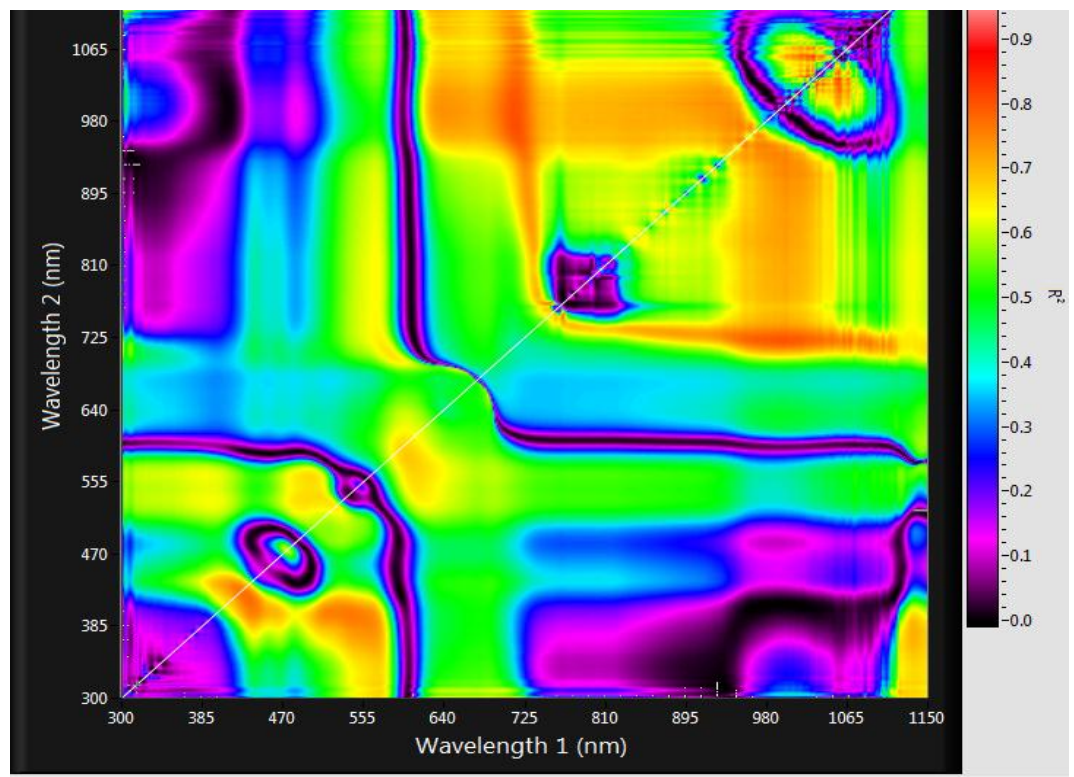

Fig.5e. Correlation matrices (contour maps) showing the coefficients of determination $\left(\mathrm{R}^{2}\right)$ for spectral index with $\mathrm{pH}$. 


\subsection{Variation of spectral reflectance indices $s$ of tomato fruits}

In (Fig.6) the results display a wide range between the minimum and maximum values for seven spectral indices for tomato fruits. The spectral index $\left(\mathrm{R}_{970} / \mathrm{R}_{950}\right)$ varied from 0.8056 to 0.8466 , the spectral index $\left(\mathrm{R}_{960} /\right.$ $\mathrm{R}_{950}$ ) varied from 0.7413 to 0.7867 , the spectral index $\left(\mathrm{R}_{970} / \mathrm{R}_{726}\right)$ varied from 0.6269 to 0.4817 and the spectral index $\left(\mathrm{R}_{992} / \mathrm{R} 940\right)$ varied from 0.6947 to 0.7710 . Both spectral indices $R_{970} / R_{726}, R_{780} / R_{740}$ and $R_{992} / R_{940}$ presented significant difference under different ripening levels.

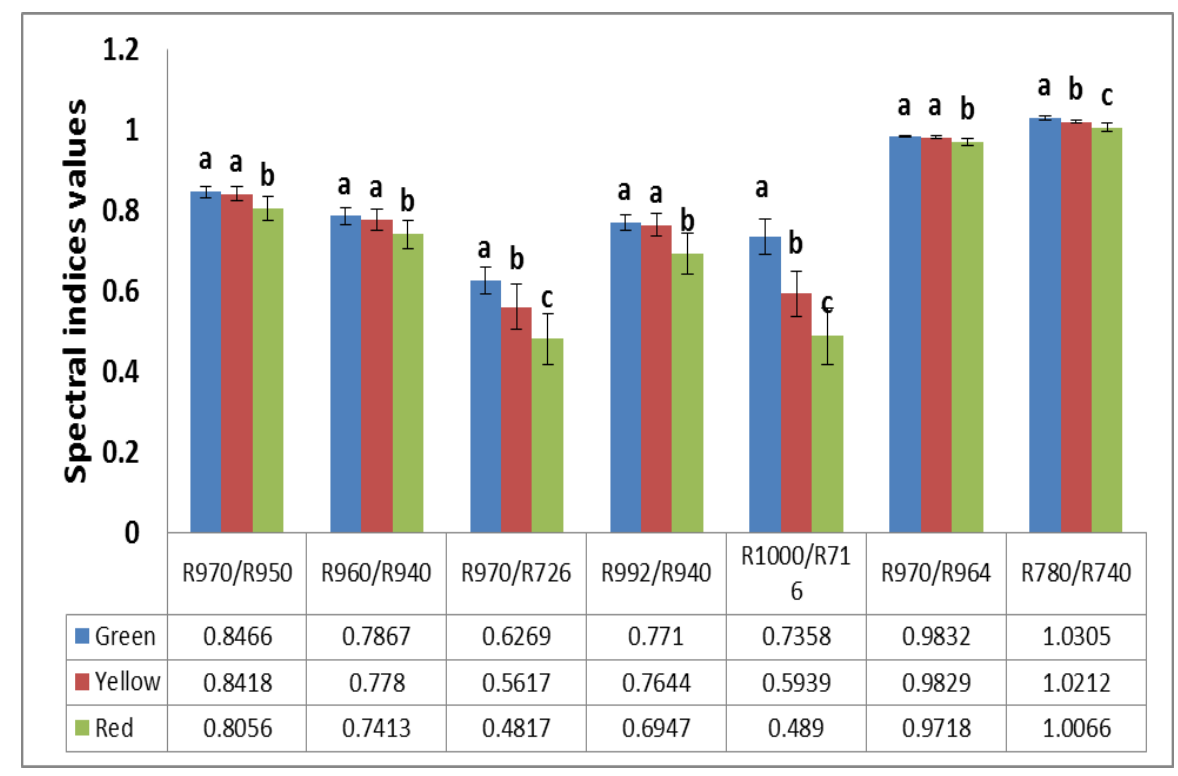

Fig. 6. Mean values (green, yellow and red) values of seven spectral indices of tomato fruits. Values with the same letter are not significantly different $(\mathrm{P} \geq$ 0.05) among cultivars according to Duncan's test. SD indicates standard deviation.

\subsection{Relationships between spectral reflectance indices and different biochemical parameters}

In Table 2 and Figs. 7, 8 and 9 seven spectral reflectance indices were significantly related to all biochemical parameters. Statistically significant relationships between all spectral reflectance indices derived from the near infrared NIR region were found for the hardness with $\mathrm{R}^{2}$ values ranging from $0.71^{* * *}$ to $0.85^{* * *}$, fruit water content with $\mathrm{R}^{2}$ values 
ranging from $0.50^{* *}$ to $0.80^{* * *}$, soluble solids content with $\mathrm{R}^{2}$ values ranging from $0.55^{* * *}$ to $0.86^{* * *}$, titratable acidity with $\mathrm{R}^{2}$ values ranging from $0.69^{* * * *}$ to $0.82^{* * *}$ and $\mathrm{pH}$ with $\mathrm{R}^{2}$ values ranging from $0.52^{* * *}$ to $0.78^{* * *}$. Generally, the spectral index $\mathrm{R}_{1000} / \mathrm{R}_{716}$, showed the highest coefficients of determination for the hardness of tomato $\left(\mathrm{R}^{2}=0.85^{* * *}\right)$, the spectral index $R_{970} / R_{964}$, showed the highest coefficients of determination for the fruit water content $\left(\mathrm{R}^{2}=0.70 * * *\right)$, soluble solids content $\left(\mathrm{R}^{2}=0.86^{* * *}\right)$ and titratable acidity $\left(\mathrm{R}^{2}=0.82^{* * *}\right)$ as well as the spectral index $R_{970} / R_{726}$, showed the highest coefficients of determination for the $\mathrm{pH}\left(\mathrm{R}^{2}=0.78^{* * *}\right)$ of tomato fruits.

Table 2. Coefficients of determination of linear regressions of five parameters (hardness, fruit water content (FWC), soluble solids content (SSC) and titratable acidity (T. Acidity and $\mathrm{pH}$ ) with seven spectral indices of the hyperspectral passive sensor of tomatoes.

\begin{tabular}{|c|c|c|c|c|c|c|c|}
\hline \multirow{2}{*}{$\begin{array}{c}\text { Fruits } \\
\text { parameters }\end{array}$} & \multicolumn{7}{|c|}{ Spectral indices } \\
\hline & $\mathbf{R}_{\mathbf{9 7 0}} / \mathbf{R}_{\mathbf{9 5 0}}$ & $\begin{array}{c}\mathbf{R}_{\mathbf{9 6 0}} / \mathbf{R}_{\mathbf{9 4}} \\
\mathbf{0}\end{array}$ & $\mathbf{R}_{\mathbf{9 7 0}} / \mathbf{R}_{\mathbf{7 2 6}}$ & $\begin{array}{c}\mathbf{R}_{\mathbf{9 9 2}} / \mathbf{R}_{\mathbf{9 4}} \\
\mathbf{0}\end{array}$ & $\begin{array}{c}\mathbf{R}_{1000} / \mathbf{R}_{71} \\
6 \\
\end{array}$ & $\mathbf{R}_{\mathbf{9 7 0}} / \mathbf{R}_{\mathbf{9 6 4}}$ & $\mathbf{R}_{\mathbf{7 8 0}} / \mathbf{R}_{\mathbf{7 4 0}}$ \\
\hline Hardness $\left(\mathrm{kg} / \mathrm{cm}^{2}\right)$ & $0.75 * * *$ & $0.71 * * *$ & $0.82 * * *$ & $0.79 * * *$ & $0.85 * * *$ & $0.77 * * *$ & $0.73 * * *$ \\
\hline FWC (\%) & $0.55 * * *$ & $0.50 * *$ & $0.60 * * *$ & $0.66 * * *$ & $0.61 * * *$ & $0.70 * * *$ & $0.67 * * *$ \\
\hline $\operatorname{SSC}(\%)$ & $0.78 * * *$ & $0.76 * * *$ & $0.81 * * *$ & $0.82 * * *$ & $0.79 * * *$ & $0.86^{* * *}$ & $0.73 * * *$ \\
\hline T.Acidity (\%) & $0.75 * * *$ & $0.69 * * *$ & $0.77 * * *$ & $0.79 * * *$ & $0.79 * * *$ & $0.82 * * *$ & $0.75^{* * *}$ \\
\hline pH & $0.75 * * *$ & $0.72 * * *$ & $0.78 * * *$ & $0.75 * * *$ & $0.77 * * *$ & $0.73 * * *$ & $0.68 * * *$ \\
\hline
\end{tabular}

$* *, * * *$ Statistically significant at $\mathrm{p} \leq 0.01 ; \mathrm{p} \leq 0.001$

Our assessment of reflectance indices as a method to assess the hardness and biochemical parameters fruits at different ripening degrees demonstrated that the selected seven indices were apparently useful for describing these parameters. Some studies have reported that different biochemical parameters can be assessed remotely and estimated simultaneously in a rapid and nondestructive method if these parameters present a significant relationship with the spectral reflectance indices (Merzlyak et al., 2003; Zude et al., 2006; Rutkowski et al., 2008; Deng et al., 2010). 

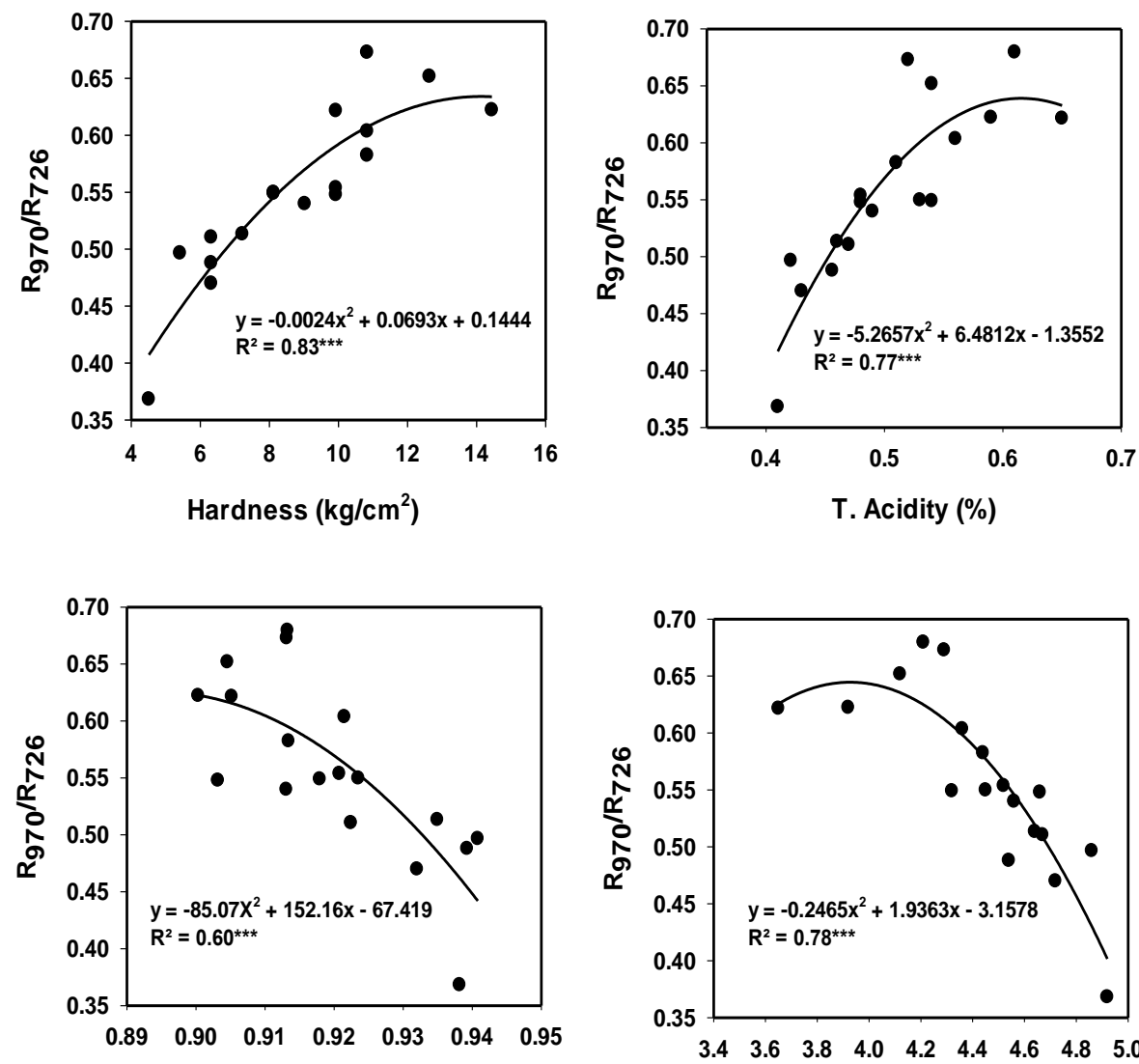

FWC (\%)
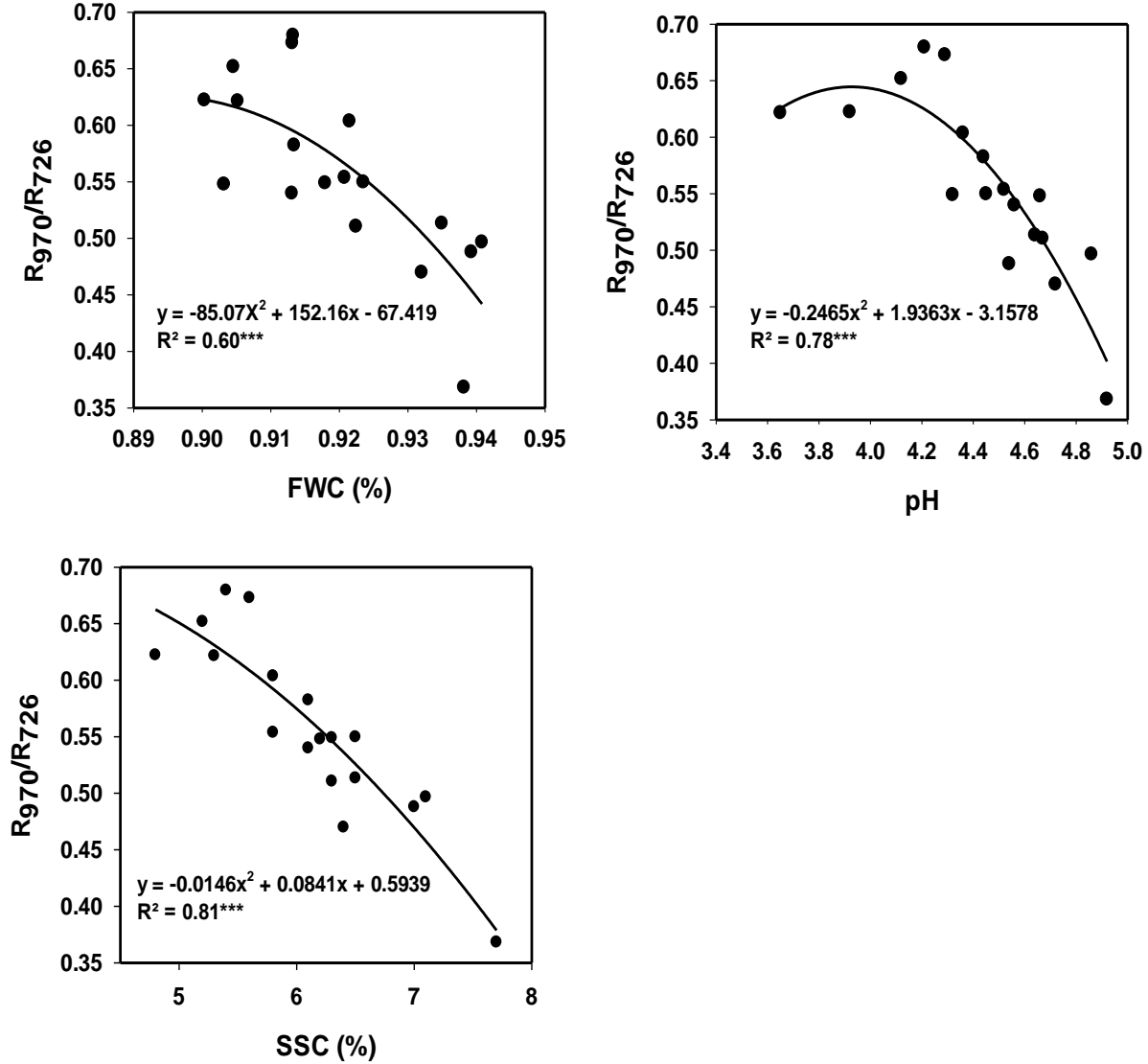

Fig. 7. The relationship between the spectral index $\left(R_{970} / R_{726}\right)$ with hardness, fruit water content (FWC), soluble solids content (SSC), titratable acidity ( $\mathrm{T}$. Acidity) and $\mathrm{pH}$ of tomato fruits. 

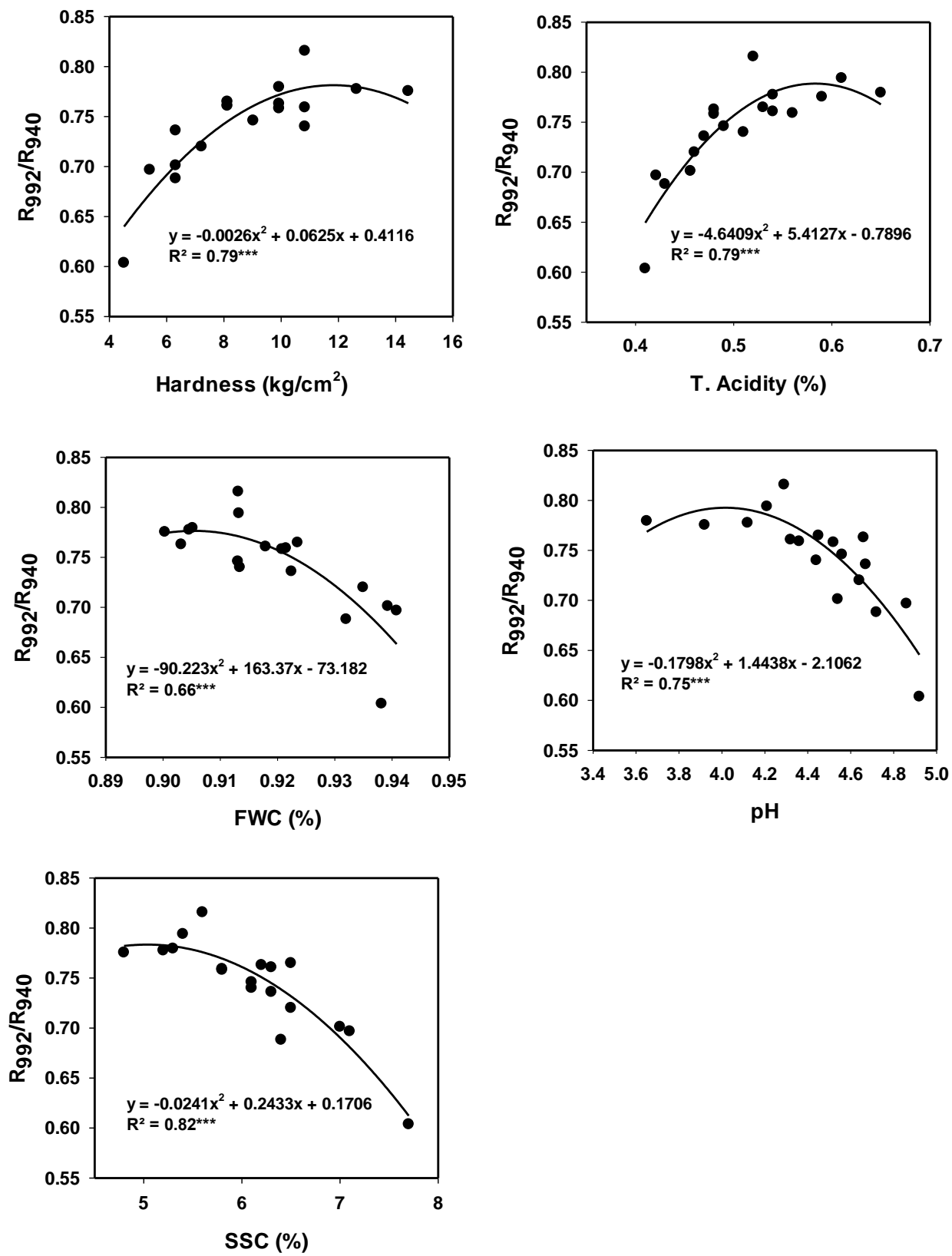

Fig. 8. The relationship between the spectral index $\left(\mathrm{R}_{992} / \mathbf{R}_{940}\right)$ with hardness, fruit water content (FWC), soluble solids content (SSC), titratable acidity ( $\mathrm{T}$. Acidity) and $\mathrm{pH}$ of tomato fruits. 

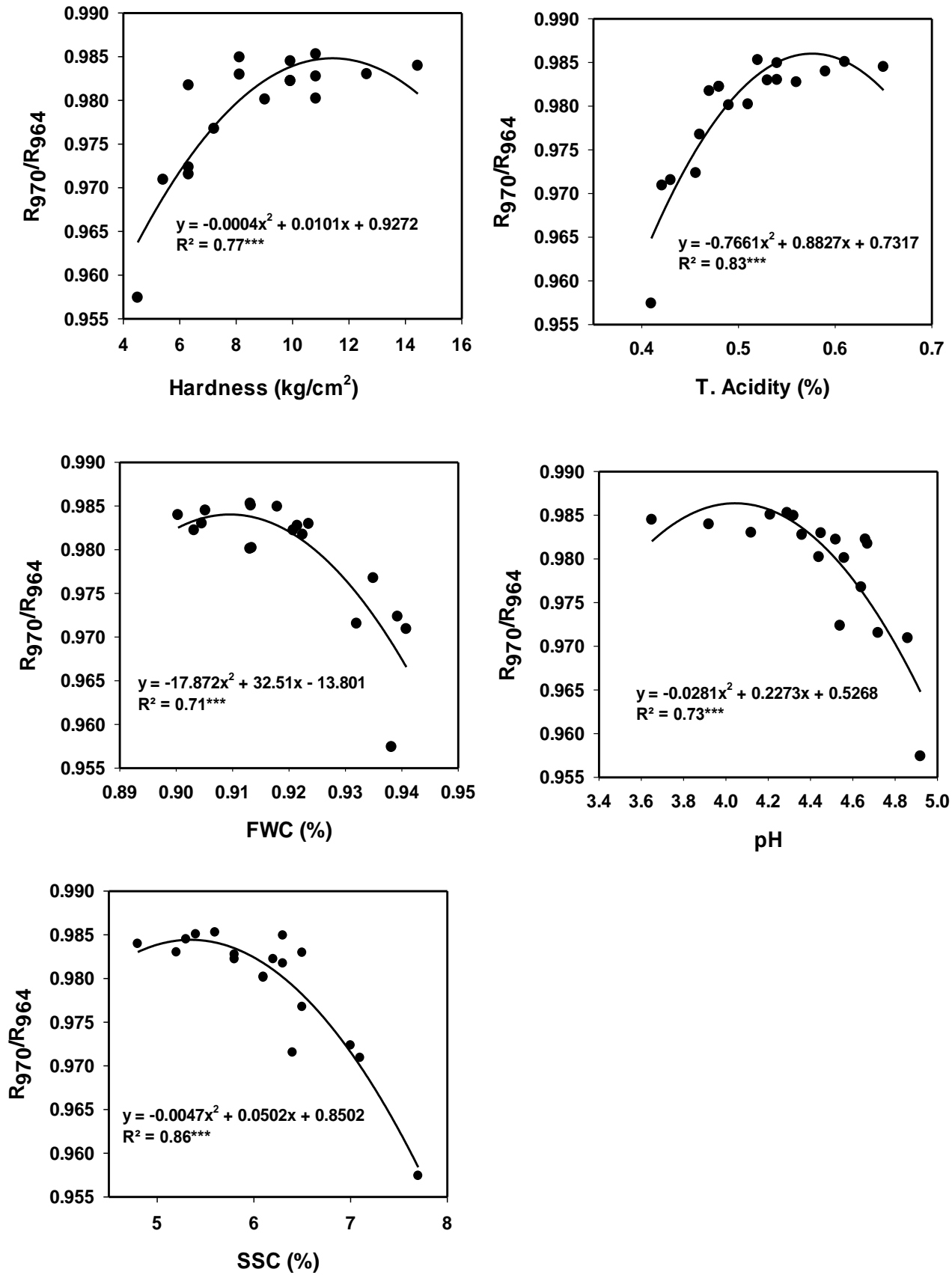

Fig. 9. The relationship between the spectral index $\left(\mathrm{R}_{970} / \mathrm{R}_{964}\right)$ with hardness, fruit water content (FWC), soluble solids content (SSC), titratable acidity ( $\mathrm{T}$. Acidity) and $\mathrm{pH}$ of tomato fruits. 
For example, Zude et al. (2006) found relations between the peak absorbance of chlorophyll $a$ at $680 \mathrm{~nm}$ and the soluble solids content $\left(\mathrm{R}^{2}\right.$ $=0.21$ ) in apple fruits. Rutkowski et al. (2008) found that the index of anthocyanin (NAI), calculated as $\left(\mathrm{R}_{780}-\mathrm{R}_{570}\right) /\left(\mathrm{R}_{780}+\mathrm{R}_{570}\right)$, was significantly related to titratable acid $\left(\mathrm{R}^{2}=0.66\right)$ in 'Golden Delicious' apples. Deng et al. (2010) found that the reflectance spectrum at $988 \mathrm{~nm}$ was significantly related to the soluble solids content $\left(R^{2}=0.15\right)$ in orange fruits. Our results for spectral reflectance indices presented stronger relationships with hardness and biochemical parameters of tomato fruits compared to the above indices.

\section{CONCLUSIONS}

The results show that changes in mechanical and biochemical parameters of tomato fruits at various ripening degrees can reliably be detected using spectral reflectance indices. We have further work to establish active and passive sensor platform based on the best indicators of spectral indices for assessment the fruit ripeness.

\section{REFERENCES}

AOAC, 1980. Official methods of analysis. 13th Ed. Association of official analytical chemists Washington, D.C, USA.

Chan, H.T. and Kwok, S.C.M., 1975. Importance of enzyme inactivation prior to extraction of sugars from papaya. J. Food. Sci. 40, 770-774.

Clément, A., Dorais, M. and Vernon, M, 2008. Nondestructive measurement of fresh tomato lycopene content and other physicochemical characteristics using visible-NIR spectroscopy, J. Agric. Food Chem. 56: 9813 - 9818.

Deng, L., He, S., Yi, S., Zheng, Y., Xie, R., Zhang, X. and Mao, S., 2010. Study on synchronous correlation between fruit characteristic spectrum and the parameter of internal quality for Hamlin sweet orange fruit. Spectrosc. Spectr. Anal. 30, 1049-1052.

Elsayed, S., Mistele, B. and Schmidhalter, U., 2011. Can changes in leaf water potential be assessed spectrally? Funct. Plant Biol. 38, 523-533. 
Elsayed, S., Elhoweity, M. and Schmidhalter, U., 2015a. Normalized difference spectral indices and partial least squares regression to assess the yield and yield components of peanut. Aust. J. Crop Sci. 9, 976-986.

Elsayed, S., Rischbeck, P. and Schmidhalter, U., 2015b. Comparing the performance of active and passive reflectance sensors to assess the normalized relative canopy temperature and grain yield of drought-stressed barley cultivars. Field Crops Res.177, 148-160.

Erdle, K., Mistele, B. and Schmidhalter, U., 2011. Comparison of active and passive spectral sensors in discriminating biomass parameters and nitrogen status in wheat cultivars. Field Crop Res. $124,74-84$.

Jha, S.N., Jaiswal, P., Narsaiah, K., Gupta, M., Bhardwaj, R., Singh, A.K., 2012. Non-destructive prediction of sweetness of intact mango using near infrared spectroscopy. Sci. Hortic. 138, 171-175.

Lizada M.C.C., 1993. Mango. In: Seymour G.B, Taylor J.E, Tucker G.A, editors. Biochemistry of fruit ripening. London: Chapman and Hall. p. 257-271.

Medlicott, A.P., Bhogal, M., Reynolds, S.B., 1986. Changes in peel pigmentation during ripening of mango fruit (Mangifera indica var. Tommy Atkins). Ann of Appl. Biol, 109, 651-656.

Merzlyak, M., Solovchenko, A., Gitelson, A., 2003. Reflectance spectral features and non-destructive estimation of chlorophyll, carotenoid and anthocyanin content in apple fruit. Postharvest Biol. Tec. 27, 197-211.

Mistele, B., Elsayed, S. and Schmidhalter, U., 2012. Assessing water status in wheat under field conditions using laser induced chlorophyll fluorescence and hyperspectral measurements. 11th International Conference on Precision Agriculture. Indianapolis, Indiana USA. 
Mistele B. and Schmidhalter U, 2008. Estimating the nitrogen nutrition index using spectral canopy reflectance measurements. Eur J Agron 29:184-190.

Moghimi, A., Aghkhani, M.H, Sazgarnia, A. and Sarmad, M., 2010. Vis/Nir spectroscopy and chemometrics for the prediction of soluble solids content and acidity $(\mathrm{pH})$ of kiwifruit. Biosystems Eng. 106, 295-302.

Nagy, A., Riczu, P. and Tamás, J., 2016. Spectral evaluation of apple fruit ripening and pigment content alteration. Sci. Hort. 201, $256-$ 264.

Peñuelas, J., Isla, R., Filella, I. and Araus, J.L., 1997. Visible and near infrared reflectance assessment of salinity effects on barley. Crop Sci. 37, 198-202.

Rutkowski, K.P., Michalczuk, B. and Konopacki, P., 2008. Nondestructive determination of 'golden delicious' apple quality and harvest maturity. J. Fruit Ornam. Plant Res.16, 39-52.

Willcox JK, Catignani GL. and Lazarus S. 2003. Tomatoes and cardiovascular health. Crit Rev Food Sci Nutr. 43:1 - 18

Zude, M., Herold, B., Roger, J.M., Bellon-Maurel, V. and Landahl, S., 2006. Non-destructive tests on the prediction of apple fruit flesh firmness and soluble solids content on tree and in shelf life. J. Food Eng. 77, 254-260.

$$
\text { الملخص العربي }
$$
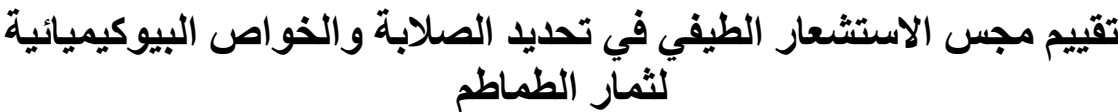

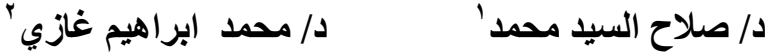

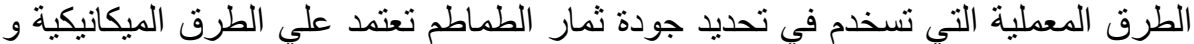

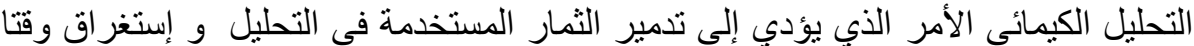
طويلا في إجر اء عملية التحليل و زيادة التكلفة و كذللك عدم السر عة في إنخاذ التيل القرار لتحديد جودة الثمار سو اء في الحقل أو ما بعد عملية الحصاد. 'أستاذ مساعد الهندسة الزراعية ـ معهد الدراسات والبحوث البيئية - جامعة مدينة السادات. 'مدرس بقسم الهنسة الزراعية ـ كلية الزراعة - جامعة المنصورة 
وبالمثل، لتحديد جودة كميات كبيرة من ثمار الطماطم المعدة للتصدير هذا ينطلب العديد من التصن

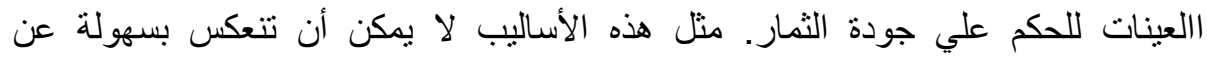

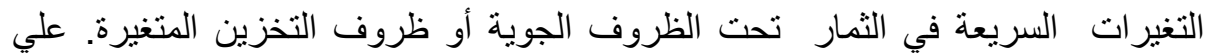

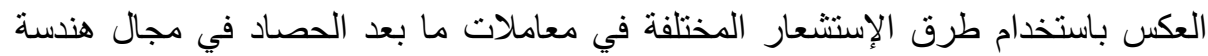
التصنيع قديؤدي الي سرعة إنخاذ القرار في تحديد درجة نضج الثمار وسهولة التدريج مما يؤدي الي تقليل الفقد و التكلفة.

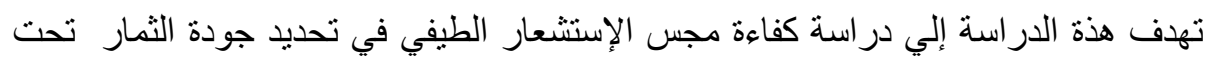

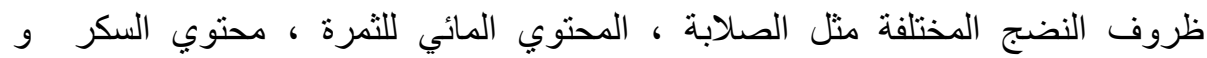

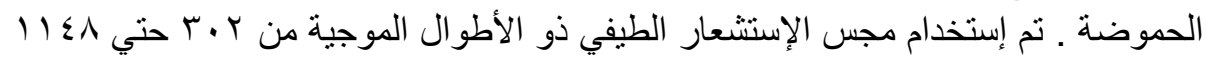

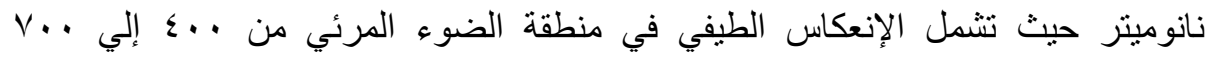

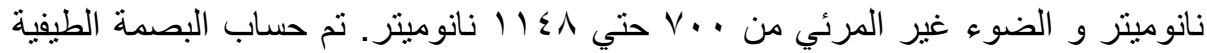

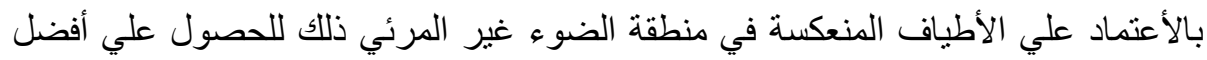
مؤشر طيفي كمدلول علي صفات الجودة تحت الدراسة. تم إجر اء ثلاث قياسات التات لتقدير

الأنعكاسات الطيفية لكل ثمرة تحت مر احل نضج مختلفه مع وضع الثمار علي جسم أسود

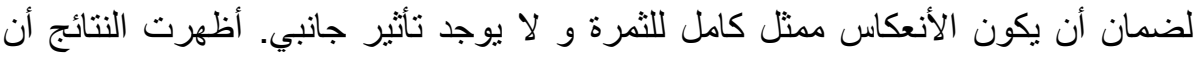

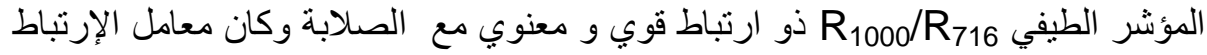

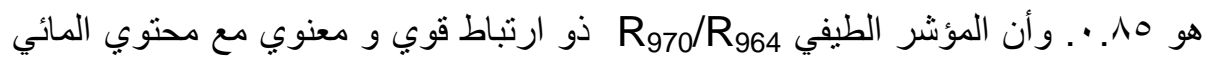

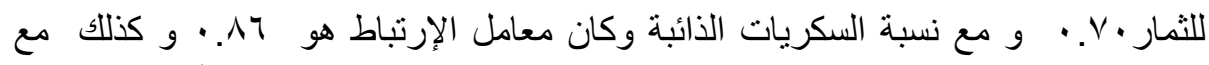

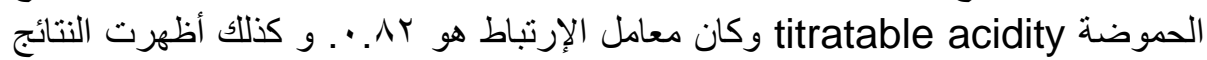
أن المؤشر الطيفي R

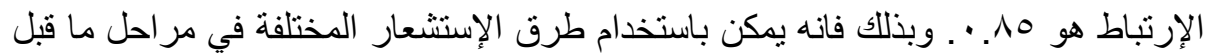

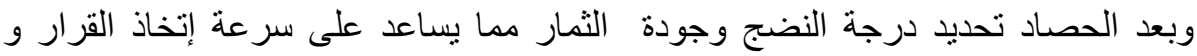
كذلك تقليل الفقد و التكلفة. 